\title{
New markers for old stains: stable mRNA markers for blood and saliva identification from up to 16-year-old stains
}

\author{
Dmitry Zubakov • Mieke Kokshoorn • \\ Ate Kloosterman • Manfred Kayser
}

Received: 19 November 2007 / Accepted: 17 April 2008 / Published online: 2 July 2008

(C) The Author(s) 2008

\begin{abstract}
In forensic science, the unequivocal identification of the cellular origin of crime scene samples used for DNA profiling can provide crucial information for crime scene reconstruction. We have previously shown that various mRNA markers from genes with expression patterns specific for blood and saliva can be established from whole-genome expression analysis of time-wise degraded samples and were stable enough to specifically identify blood and saliva stains up to 180 days of age. Here, we showed that nine blood-specific and five saliva-specific mRNA markers can be amplified successfully and reliably in much older blood (13-16 years) and saliva (2-6 years) stains, respectively, suggesting their suitability for tissue identification in forensic case work. Moreover, our findings imply that forensic RNA testing can be reliable and robust if degraded samples are considered in the marker ascertainment procedure, with promising expectations beyond tissue identification purposes.
\end{abstract}

Miscellaneous The gene name SPRR3 needs to be replaced by SPRR2A in our previous publication Zubakov et al. Int J Legal Med 122(2): 135-142, 2008.

Electronic supplementary material The online version of this article (doi:10.1007/s00414-008-0249-z) contains supplementary material, which is available to authorized users.

D. Zubakov $\cdot$ M. Kokshoorn $\cdot$ M. Kayser $(\bowtie)$

Department of Forensic Molecular Biology,

Erasmus University Medical Center Rotterdam,

Dr. Molewaterplein 50,

3015 GE Rotterdam, The Netherlands

e-mail: m.kayser@erasmusmc.nl

\section{A. Kloosterman}

Department of Biological Trace Examination,

Netherlands Forensic Institute,

The Hague, The Netherlands
Keywords Body fluid · Cellular origin · mRNA markers . Blood $\cdot$ Saliva $\cdot$ RNA stability

\section{Introduction}

The reliable identification of the cellular origin of crime scene samples used for DNA profiling can potentially provide crucial information for crime scene reconstruction. Although RNA is generally believed to be highly unstable and prone to degradation due to the action of ribonucleases and environmental factors such as $\mathrm{pH}$, UV light, and moisture [1], recent advances in molecular forensics revealed a number of RNA markers successfully amplifiable under certain postmortem and/or in vitro conditions [2-6]. For instance, Karlsson et al. [7] detected mRNA from the $\beta$-actin and GAPDH genes in 27-year-old blood stains; however, the study design did not ensure that polymerase chain reaction (PCR) amplification products truly originated from cDNA templates and not from contaminating genomic DNA. We have previously shown that various mRNA markers from genes with expression patterns specific for blood and saliva can be established from wholegenome expression analysis of time-wise degraded samples, and respective mRNA markers were able to specifically identify blood and saliva stains of up to 180 days of age [8]. In the present study, we tested the behavior of the previously identified mRNA markers in much older blood and saliva stains as prerequisite for future application to forensic case work. Empirical testing of mRNA marker stability is essential because usually the age of a crime scene sample is originally unknown. Therefore, and in prerequisite for practical forensic applications, it needs to be proven that the particular mRNA markers intended for 
forensic use can be amplified successfully under a wide range of sample conditions including sample age.

\section{Materials and methods}

Blood and saliva samples were collected from nine and 12 healthy volunteers of Western European origin, respectively, under their informed consent. Blood was spotted onto a clean cotton tissue and saliva was collected by absorption with cotton or cellulose swabs. Prior to RNA isolation, dried specimens were stored at ambient temperature in dustfree, nonhumid conditions (subjected to normal daylight) for 13-16 and 2-6 years for blood and saliva stains, respectively. Pieces of blood-stained cotton tissue used for RNA extraction ranged in size from $\sim 0.05$ to $\sim 0.75 \mathrm{~cm}^{2}$; in case of saliva samples, an amount of material equivalent to one standard cotton swab was used. Total RNA isolation was performed with QIAGEN RNeasy Mini Kit (QIAGEN Benelux B.V., Netherlands) according to the manufacturer's instructions with minor modifications as described previously [8]. RNA extracts were treated with Turbo DNase kit from Ambion (Applied Biosystems, Netherlands). The quality and quantity of RNA was assessed by capillary electrophoresis on Agilent 2100 Bioanalyzer automated analysis system (Agilent Technologies, Palo Alto, CA, USA). Complementary DNA synthesis was carried out with Invitrogen SuperScript ${ }^{\circledR}$ III First Strand Synthesis System for reverse-transcriptase (RT)-PCR (Invitrogen BV, Netherlands) using random hexamer primers according to manufacturer's instructions. Reactions without addition of reverse transcriptase (RT(-) controls) were performed alongside with cDNA synthesis of each sample and used in subsequent procedures to control the potential genomic DNA contamination. Real-time PCR reactions with the Platinum SYBR Green qPCR Kit (Invitrogen BV, Netherlands) were performed in $15-\mu \mathrm{L}$ reaction volume in triplicates on $\mathrm{ABI} 7300$ PCR machine (Applied Biosystems, Netherlands) using previously described oligonucleotide primers for nine genes with blood-specific expression pattern (ALOX5AP, AMICA1, AQP9, ARHGAP26, C1QR1, C5R1, CASP1, MNDA, and $N C F 2$ ) and for five genes with saliva-specific expression pattern (SPRR1A, SPRR2A, KRT4, KRT6A, and KRT13) [8]. The following cycling parameters were used during PCR: initial denaturation at $94^{\circ} \mathrm{C}$ for $10 \mathrm{~min}$, followed by 45 cycles of denaturation at $94^{\circ} \mathrm{C}$ for $15 \mathrm{~s}$, and a final annealing-elongation at $60^{\circ} \mathrm{C}$ for $30 \mathrm{~s}$. Melting profiling and agarose gel electrophoresis were used to confirm the specificity of the amplification. Messenger RNA markers were additionally tested in cDNA from 2-year-old blood samples that was derived from random hexamer primers, oligo $(\mathrm{dT})_{20}$ primers, and gene-specific primers, respectively, to test for sensitivity effects of the reverse-transcription technique in respect of the mRNA markers tested. All three reverse-transcription methods allowed successful amplification of all mRNA markers and on a similar level of sensitivity (data not shown). However, experimental reproducibility was slightly better for cDNA produced by random hexamer primers compared to gene-specific or oligo(dT) $)_{20}$ primers (data not shown) so that we decided to apply random hexamer primers for cDNA synthesis in this study.

\section{Results and discussion}

In spite of the severe RNA degradation (see Supplementary Fig. S1), we were able to obtain PCR products ranging in length from 93 to $195 \mathrm{bp}$ from cDNA of all genes analyzed in old blood and saliva stains (Fig. 1a, b). RT(-) controls were negative in all cases and the size of the PCR amplicons revealed corresponded for all genes to the intronless cDNA templates providing strong evidence for the absence of genomic DNA contamination. The experimental setup included approximate estimation of the marker's detection sensitivity relative to the starting amount of bloodstain material. According to Agilent 2100 Bioanalyzer measurements, $0.5-1.0 \mathrm{ng}$ of total RNA was yielded from $\sim 0.75 \mathrm{~cm}^{2}$ of bloodstain. After cDNA synthesis, this amount was divided into an equal number of aliquots to perform 45 PCRs (three replicates $\times$ nine genes +

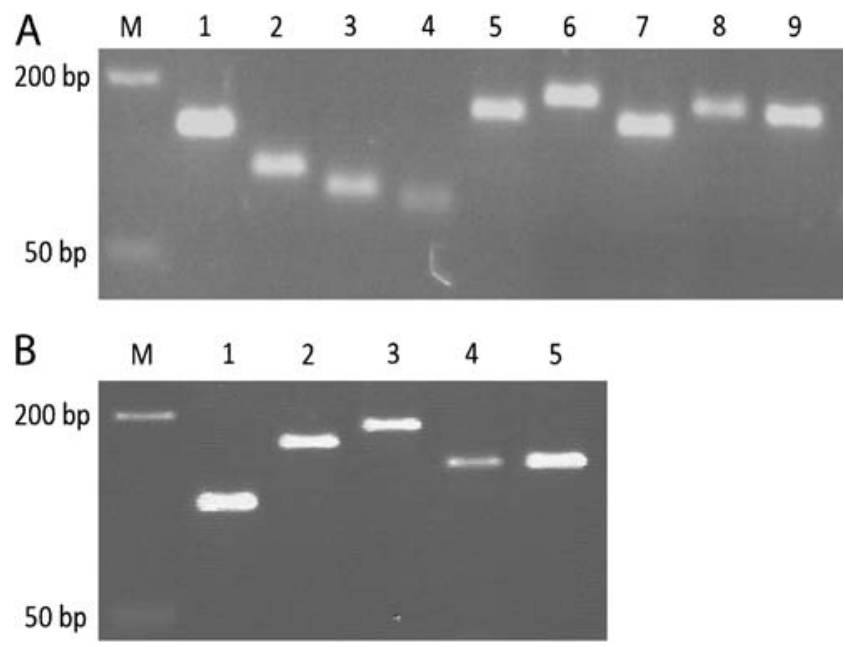

Fig. 1 Agarose gel electrophoresis of PCR products from a nine mRNA markers with blood-specific expression pattern as obtained from RNA extracted from a 13-16-year-old bloodstain with lanes 1-9 corresponding to mRNA markers from the following genes: $C A S P 1$, AMICA1, C1QR1, ALOX5AP, AQP9, C5AR1, ARHGAP26, NCF2, and $M N D A$, respectively, and b five mRNA markers with salivaspecific expression pattern as obtained from RNA extracted from a 6-year-old saliva stain with lanes $1-5$ corresponding to mRNA markers from the following genes: KRT4, KRT6A, KRT13, SPRR1A, and $S P R R 2 A$, respectively. Lane $M$ corresponds to a molecular-size ladder 
Table 1 Results of RT-PCR amplification of mRNA markers from genes with blood-specific expression pattern in stains of 13-16 years of age

\begin{tabular}{|c|c|c|c|c|c|c|c|c|}
\hline Gene name & $\begin{array}{l}\text { Average } \\
C_{\mathrm{t}}^{\mathrm{a}}\end{array}$ & $\mathrm{SD}^{\mathrm{a}}$ & $\begin{array}{l}\text { Reproducibility } \\
\text { between } \\
\text { individuals }{ }^{\mathrm{a}, \mathrm{b}}(\%)\end{array}$ & $\begin{array}{l}\text { Reproducibility } \\
\text { within individuals }{ }^{\mathrm{a}, \mathrm{c}} \\
(\%)\end{array}$ & $\begin{array}{l}\text { Average } \\
C_{\mathrm{t}}^{\mathrm{d}}\end{array}$ & $\mathrm{SD}^{\mathrm{d}}$ & $\begin{array}{l}\text { Reproducibility } \\
\text { between } \\
\text { individuals } \\
\text { b,d }(\%)\end{array}$ & $\begin{array}{l}\text { Reproducibility } \\
\text { within individuals }{ }^{\mathrm{c}, \mathrm{d}} \\
(\%)\end{array}$ \\
\hline$N C F 2$ & 28.8 & 1.0 & 100 & 100 & 30.9 & 1.4 & 100 & 80 \\
\hline$M N D A$ & 29.9 & 1.0 & 100 & 100 & 33.0 & 2.0 & 80 & 60 \\
\hline CASP1 & 33.0 & 1.2 & 100 & 90 & 33.9 & 1.1 & 80 & 60 \\
\hline$C 1 Q R 1$ & 32.1 & 1.6 & 100 & 90 & 34.5 & 0.7 & 70 & 40 \\
\hline ARHGAP26 & 33.7 & 0.8 & 100 & 100 & 34.6 & 0.5 & 80 & 60 \\
\hline$A M I C A 1$ & 31.7 & 1.1 & 100 & 100 & 33.0 & 0.8 & 80 & 40 \\
\hline$A L O X 5 A P$ & 34.3 & 3.4 & 100 & 90 & - & - & - & - \\
\hline$A Q P 9$ & 32.9 & 1.1 & 100 & 100 & - & - & - & - \\
\hline C5R1 & 32.0 & 1.0 & 100 & 90 & - & - & - & - \\
\hline
\end{tabular}

${ }^{\mathrm{a}}$ Based on RNA was extracted from $0.75-\mathrm{cm}^{2}$ blood stains

${ }^{b}$ Reproducibility between individuals was defined as the percentage of successful amplifications in at least one of three technical replicates averaged across all nine individuals tested

${ }^{\mathrm{c}}$ Reproducibility within individuals was defined as the percentage of successful amplification in three technical replicate RT-PCRs for the same individual averaged across all nine individuals tested; a Kruskal-Wallis test identified no outliers in the reproducibility of technical replicates with $p<0.05$, i.e., variation among RT-PCR replicates was random

${ }^{\mathrm{d}}$ Based on RNA was extracted from $0.05-\mathrm{cm}^{2}$ blood stains

no template and $\mathrm{RT}(-)$ control reactions for each gene), i.e., each reaction contained the amount of template equivalent to as little as $\sim 16$ pg of RNA. RT-PCR threshold cycle $\left(C_{\mathrm{t}}\right)$ values were in the range of 28.8-34.3 for different bloodspecific mRNA markers tested and a high rate of successful amplification was observed (Table 1). Reproducibility between individual samples was $100 \%$ for all mRNA markers and reproducibility within individuals among three technical replicates was $100 \%$ for five mRNA markers and $90 \%$ for four (Table 1). The experiments with the bloodstains of much smaller size of $\sim 0.05 \mathrm{~cm}^{2}$ were carried out in a similar manner. However, in this case, RNA was not quantified because of the expected subpicogram yield, which is far below the detection limit of the device used for quantification. As expected, decreasing the starting amount of material significantly reduced the success rate of PCR amplifications: no PCR products were obtained anymore for three markers (ALOX5AP, AQP9, and C5R1), whereas the other markers, showed higher $C_{\mathrm{t}}$ values (30.9$34.6)$ and less reproducibility between $(70-100 \%)$ as well as within $(40-80 \%)$ individuals compared with the tests from larger blood stains for the respective markers (Table 1). However, at least one blood-specific mRNA marker (NCF2), which showed the lowest $C_{\mathrm{t}}$ value of all markers in the large and small stain analyses, could be detected from the small-sized blood stains of $\sim 0.05 \mathrm{~cm}^{2}$ with $100 \%$ between-individual and $80 \%$ within-individual reproducibility. Results derived from the $\sim 0.05-\mathrm{cm}^{2}$ blood stains indicate that the amount of RNA in the samples was at the limit of the sensitivity of the applied regular PCR-based detection method (perhaps with the exception of NCF2).

The yield of total RNA from old saliva stains was in a range of 50-200 ng per sample. The amount of cDNA template used in individual PCR reactions was equivalent

Table 2 Results of RT-PCR amplification of mRNA markers from genes with saliva-specific expression pattern in stains of 2-6 years of age

\begin{tabular}{llccc}
\hline Gene name & Average $C_{\mathrm{t}}$ & SD & $\begin{array}{l}\text { Reproducibility between } \\
\text { individuals }^{\mathrm{a}}(\%)\end{array}$ & $\begin{array}{c}\text { Reproducibility within } \\
\text { individuals }\end{array}$ \\
\hline KRT4 & & 90 & 90 \\
KRT6A & 28.3 & 3.6 & 100 & 80 \\
KRT13 & 31.5 & 3.8 & 100 & 90 \\
SPRR $1 A$ & 28.6 & 3.6 & 100 & 100 \\
SPRR $2 A$ & 31.3 & 2.3 & 100 & 90 \\
\end{tabular}

\footnotetext{
${ }^{a}$ Reproducibility between individuals was defined as the percentage of successful amplifications in at least one of three technical replicates averaged across all 12 individuals tested

${ }^{\mathrm{b}}$ Reproducibility within individuals was defined as the percentage of successful amplification in three technical replicate RT-PCRs for the same individual averaged across all 12 individuals tested; a Kruskal-Wallis test identified no outliers in the reproducibility of technical replicates with $p<0.05$, i.e., variation among RT-PCR replicates was random
} 
to $\sim 25 \mathrm{ng}$ of total RNA (25 individual reactions from one sample). RT-PCR $C_{\mathrm{t}}$ values for saliva-specific mRNA markers were in the range of 28.3-31.5 (Table 2), which is similar to the analysis of blood-specific markers from the $0.75-\mathrm{cm}^{2}$ stains but with higher standard deviations. Reproducibility between individuals was high $(100 \%$ for four markers and $90 \%$ for one) but slightly more variable $(80-100 \%)$ within individuals (Table 2). It is worth noting that, although $C_{\mathrm{t}}$ values were comparable, the amount of total RNA was about $1,500 \times$ higher in the saliva analyses compared with the $0.75-\mathrm{cm}^{2}$ blood stain analyses.

Over all, we expect the achieved mRNA marker sensitivities, which were higher for blood-specific mRNA markers (picogram range of total RNA) than for salivaspecific ones (nanogram range of total RNA), matching the demands of most forensic cases requiring blood and saliva identification from crime scene samples. Although technical modifications like alternative primer design, nested PCR, or RNA amplification prior to PCR might further increase the test sensitivity, the latter two also bear extra risks of contamination-induced artifacts that need to be avoided.

To conclude, our present data together with those from our previous study [8] demonstrate that nine mRNA markers with blood-specific expression pattern (ALOX5AP, AMICA1, AQP9, ARHGAP26, C1QR1, C5R1, CASP1, $M N D A$, and NCF2) and five mRNA markers with salivaspecific expression (SPRR1A, SPRR2A, KRT4, KRT6A, and $K R T 13)$ are sufficiently stable and sensitive to enable the detection of blood and saliva in samples of a wide age range, from freshly dried up to at least 16 and 6 years of age for blood and saliva stains, respectively. This provides sufficient evidence in favor of their application to forensic cases involving stains of unknown age, at least those kept under similar environmental conditions as applied here. However, additional environmental factors such as humidity and UV radiation, which could potentially influence in vitro mRNA marker stability in addition to sample age, require further investigation. We additionally showed that the detection limit for our blood-specific mRNA markers was significantly lower than that of our saliva-specific markers suggesting that the cellular origin of biological stains might be a considerable factor (amongst others) influencing RNA stability. Many pathophysiological conditions but also human-visible traits that are potentially useful for death-trauma examination or suspect-victim identification in forensics are associated with gene expression changes. Therefore, the use of biological stains as a source of stable mRNA markers for transcription analysis in forensic and medico-legal investigations opens prospects that lie far beyond the tissue identification purpose presented here.

Acknowledgements We are grateful to all volunteers who provided samples for this study. This study was supported by the Netherlands Forensic Institute, the Erasmus University Medical Center Rotterdam, and by additional funds from the Fonds Schiedam Vlaardingen to support forensic molecular biology at Erasmus MC.

Open Access This article is distributed under the terms of the Creative Commons Attribution Noncommercial License which permits any noncommercial use, distribution, and reproduction in any medium, provided the original author(s) and source are credited.

\section{References}

1. van Hoof A, Parker R (2002) Messenger RNA degradation: beginning at the end. Curr Biol 12:285-287

2. Bauer M, Kraus A, Patzelt D (1999) Detection of epithelial cells in dried blood stains by reverse transcriptase-polymerase chain reaction. J Forensic Sci 44:1232-1236

3. Juusola J, Ballantyne J (2003) Messenger RNA profiling: a prototype method to supplant conventional methods for body fluid identification. Forensic Sci Int 135(2):85-96

4. Alvarez M, Juusola J, Ballantyne J (2004) An mRNA and DNA co-isolation method for forensic casework samples. Anal Biochem 335(2):289-298

5. Juusola J, Ballantyne J (2005) Multiplex mRNA profiling for the identification of body fluids. Forensic Sci Int 152(1):1-12

6. Heinrich M, Matt K, Lutz-Bonengel S, Schmidt U (2007) Successful RNA extraction from various human postmortem tissues. Int J Legal Med 121:136-142

7. Karlsson H, Guthenberg C, von Dobeln U, Kristenssson K (2003) Extraction of RNA from dried blood on filter papers after long-term storage. Clin Chem 49:979-981

8. Zubakov D, Hanekamp E, Kokshoorn M, van IJcken W, Kayser M (2008) Stable RNA markers for identification of blood and saliva stains revealed from whole genome expression analysis of timewise degraded samples. Int J Legal Med 122(2):135-142 